\title{
Dye-Labeled Polyacryloyl Hydrazide-Ag Nanoparticle Fluorescent Probe for Ultrasensitive and Selective Detection of Au Ion
}

\author{
Rewati Raman Ujjwal, ${ }^{\dagger}$ Chandan Sona, ${ }^{\dagger}$ Suman Debnath, ${ }^{\dagger}$ Prem Narayan Yadav, ${ }^{\ddagger}$ \\ and Umaprasana Ojha* ${ }^{\dagger}$
}

${ }^{\dagger}$ Department of Chemistry, Rajiv Gandhi Institute of Petroleum Technology, Ratapur Chowk, Rae Bareli, Uttar Pradesh 229316, India

${ }^{\ddagger}$ Department of Pharmacology, CSIR-Central Drug Research Institute, Sector-10, Jankipuram Extension, Sitapur Road, Lucknow, Uttar Pradesh 226031, India

\section{Supporting Information}

ABSTRACT: The efficiency of a fluorescence sensing device based on metal-enhanced fluorescence (MEF) is dependent on the optimization of interaction between the fluorophore and the metal nanoparticle (NP). Herewith, ultrasensitive and selective turn-on sensing of $\mathrm{Au}^{3+}$ is achieved by using a suitable combination of fluorophore and metal NP system through sequential MEF effect. Dansyl hydrazide-tagged Ag NPs in the polyacryloyl hydrazide cavity are utilized to sense the picomolar concentration of $\mathrm{Au}^{3+}$ in aqueous media. We demonstrated that the selective $\mathrm{Au}^{3+}$ sensing is due to the selective deposition of $\mathrm{Au}$ on the Ag NP surface over the 16 other metal ions studied. The sensitivity is assigned to the strong overlapping of the emission band of the fluorophore with the surface plasmon band of the $\mathrm{Au}$ and improvement of fluorescence signal through successive MEF by $\mathrm{Ag}$ and $\mathrm{Au}$ colloids. The sensing is associated with a fivefold increase in fluorescence intensity and appearance of violet color of the solution. These luminescent $\mathrm{Ag}-\mathrm{Au}$ bimetallic NPs may be utilized to trace cancer cells in biological systems and for cell imaging applications.

\section{INTRODUCTION}

Gold $(\mathrm{Au})$ is precious to human being since ancient times because of its esthetic qualities. Au cations have also displayed promising medicinal qualities and are used in the treatment of tuberculosis and rheumatoid arthritis. ${ }^{1}$ At the same time, the $\mathrm{Au}$ cations, especially $\mathrm{Au}^{3+}$, are reported to be toxic toward human ${ }^{2}$ and aquatic species. ${ }^{3}$ The above toxicity of soluble $\mathrm{Au}^{3+}$ is attributed to its selective binding ability toward $\mathrm{DNA}^{4}$ and enzymes. ${ }^{5} \mathrm{Au}^{3+}$ is responsible for enzyme depletion and protein denaturation against selective cellular targets and lysosomal dysfunction, which subsequently results in DNA and membrane damage. ${ }^{6} \mathrm{Au}^{3+}$ also promotes the oxidative DNA damage by catalyzing the free-radical generation of various chemical entities frequently used in biochemical and biological studies. ${ }^{7}$ The $\mathrm{Au}$ salts cause serious damage to kidney, liver, and peripheral nervous system. ${ }^{8}$ Therefore, sensing tools to determine the concentration of $\mathrm{Au}^{3+}$ selectively with high sensitivity are desirable. In this regard, a number of reports on the sensing of $\mathrm{Au}$ cations in both aqueous ${ }^{9}$ and organic ${ }^{10}$ media are available in the literature. Sensing of $\mathrm{Au}$ ion in aqueous media is advantageous to detect the contamination in biological systems. Out of the various modes of sensing available for the detection of $\mathrm{Au}^{3+}$, the fluorescence mode is advantageous because of its operational simplicity and ultrasensitivity. ${ }^{11} \mathrm{Au}$ nanoparticles (NPs) are known to be strong fluorescence quenchers because of the associated energy-transfer processes; $^{12}$ therefore, turn-off fluorescence sensors for the detection of $\mathrm{Au}$ are reported in the literature. Turn-on sensors for $\mathrm{Au}^{3+}$ are also reported in the literature in which the $\mathrm{Au}^{3+}$ ion acts as a catalyst and chemically transforms the nonfluorescent probe to a fluorescent one. ${ }^{13}$ However, the sensitivity is limited to micromolar concentrations because $\left[\mathrm{Au}^{3+}\right]$ in above range is necessary to catalyze the sensing reaction.

NP-based probes for sensing applications have gained immense attention recently because of their high detection threshold, ${ }^{14}$ low cost, fast response, high surface area, and portability. ${ }^{15}$ A range of chemical, ${ }^{16}$ optical, ${ }^{17}$ electrochemical, biological, ${ }^{18}$ and $\mathrm{pH}^{19}$ sensors based on NPs are available in the current literature. ${ }^{20}$ Nanosensors are promising especially in the area of biosensing because of the possibility of real-time and nonevasive monitoring of intracellular activities, ${ }^{21}$ tracing disease biomarkers, ${ }^{22}$ and toxic chemicals. ${ }^{23}$ Metallic NPs possessing size- and shape-dependent optical properties or surface plasmon resonance are useful in colorimetric and

Received: June 24, 2017

Accepted: July 25, 2017

Published: August 7, 2017 
fluorescence sensing applications. ${ }^{24}$ Furthermore, because surface functionalization of these metallic NPs with different ligands alters their optical properties, ${ }^{25}$ a variety of available surface-modified NPs broaden their applicability in the area of sensors. Dye labeling of the NPs is an attractive technique to impart unique emissive properties through plasmon-controlled fluorescence or metal-enhanced fluorescence (MEF) mechanism. MEF is dependent on the interaction between the fluorophore and the metal NPs, shapes and sizes of the metal NPs, and the distance between these NPs and the fluorophore. This enhancement is attributed to the radiative rate modification of the fluorophore in the close proximity of a metal NP. ${ }^{26}$ As per the common understanding, strong overlapping of the excitation/emission band of the fluorophore with the surface plasmon band of the metal NP is anticipated to induce maximum fluorescence enhancement in the system. ${ }^{27}$

Therefore, careful selection of dye and metal NP system is important to design a highly sensitive fluorescence sensing device. Herewith, a dye-labeled Ag NP system stabilized by the polyacryloyl hydrazide (PAHz) cavity is designed to sense $\mathrm{Au}^{3+}$. $\mathrm{PAHz}$ is chosen as the stabilizing agent for multiple reasons. First, instant formation of $\mathrm{Ag}$ and $\mathrm{Au}$ NPs is possible in the $\mathrm{PAHz}$ solution under room-temperature conditions. ${ }^{28}$ Second, covalent dye labeling of the PAHz-Ag NPs is possible by utilizing the swift reactivity of carbonyl hydrazide with a range of functional groups. ${ }^{29}$ Last, the PAHz cavity around the metal NPs may act as a spacer layer and provide the much needed gap between the fluorophore and the NPs. Au is known to quench the fluorescence at shorter distances $(<2 \mathrm{~nm})^{30}$ and exhibit MEF at longer distances $(\geq 20 \mathrm{~nm}) .^{31,32}$ The procedure allows cost-effective and reagent-free one-pot synthesis of dye-labeled Ag NPs. Dansyl hydrazide (DH) possessing emission maximum $(\sim 510 \mathrm{~nm})$ similar to the surface plasmon band of Au NP (525 $\mathrm{nm})$ and low (0.01) quantum yield (QY) is chosen as the fluorophore to offer strong interaction and achieve maximum sensing sensitivity through optimized MEF. $\mathrm{Ag} \mathrm{NP}$ is anticipated to induce primary MEF to the $\mathrm{DH}$ in PAHz-DH$\mathrm{Ag} \mathrm{NP}$. In the presence of $\mathrm{Au}^{3+}$, possible deposition of $\mathrm{Au}$ on $\mathrm{Ag}$ NP to form the corresponding $\mathrm{Ag}-\mathrm{Au}$ bimetallic NP in the $\mathrm{PAHz}$ cavity is expected to improve the signal through a secondary MEF and to create the possibility of turn-on sensing of Au ion. Therefore, PAHz-DH-Ag NPs are synthesized, and their efficiency in sensing $\mathrm{Au}^{3+}$ at different concentrations in aqueous media is studied. The use of these highly fluorescenceenhanced bimetallic nano-objects in cell imaging and sensing of intracellular $\mathrm{pH}$ is accessed.

\section{EXPERIMENTAL SECTION}

Materials. Methyl acrylate (SD Fine Chemicals, >99\%), potassium bromate (Merck, $>99.0 \%$ ), sodium hydrogen sulfite (Merck, 58.5-67.4\%), acrylic acid (AA, Merck, >99.0\%), sodium chloride ( $\mathrm{NaCl}$, Qualigens, $>99.9 \%)$, hydrazine hydrate (SD Fine Chemicals, 99\%), tetra- $n$-butylammonium bromide (TBAB, Merck, $\geq 98.0)$, silver nitrate $\left(\mathrm{AgNO}_{3}\right.$, Qualigens, 99\%), dansyl chloride (DC, Alfa Aesar, 97\%), dimethyl sulfoxide (DMSO, SRL-chemicals), $\mathrm{HAuCl}_{4}$ (Sigma-Aldrich, 99.99\%), $\mathrm{CuSO}_{4} \cdot 5 \mathrm{H}_{2} \mathrm{O}$ (Fisher Scientific, 98.5\%), $\mathrm{Co}\left(\mathrm{NO}_{3}\right)_{2}$ (Qualigens, >99.9\%), $\mathrm{CdCl}_{2}$ (Qualigens, >95\%), $\mathrm{HgCl}_{2}$ (Fisher Scientific, 99.9\%), $\mathrm{SnCl}_{4}$ (Fisher Scientific, 99.9\%), $\mathrm{FeSO}_{4}$. $7 \mathrm{H}_{2} \mathrm{O}$ (Fisher Scientific, 99.9\%), $\mathrm{TiO}_{2}$ (Qualigens, >99.9\%), $\mathrm{NiCl}_{2}$ (Qualigens, >99.9\%), $\mathrm{Cr}_{2}\left(\mathrm{SO}_{4}\right)_{3}$ (Qualigens, >99.9\%), $\mathrm{MgSO}_{4}$ (Merck, 99\%), $\mathrm{PbCl}_{2}$ (Qualigens, >99.9\%), $\mathrm{ZnSO}_{4}$. $7 \mathrm{H}_{2} \mathrm{O}$ (Qualigens, $>99.0 \%$ ), platinum bromide $\left(\mathrm{PtBr}_{2}\right.$, Sigma-
Aldrich, 98\%), and cesium chloride $\left(\mathrm{CsCl}_{3} \cdot 7 \mathrm{H}_{2} \mathrm{O}\right.$, Qualigens, $>99.9 \%)$ were used without further purification. Tetrahydrofuran (THF, Qualigens, 99.0\%) was refluxed over sodium metal and benzophenone overnight and distilled under a nitrogen atmosphere prior to use. Water used for the preparation of aqueous solution was obtained by deionization and filtration with a Millipore Elix-10 purification apparatus. The electrical conductivity of deionized water is $0.0054 \mathrm{mS} / \mathrm{cm}$.

Characterization. A LabIndia UV-VIS 3200 instrument was used to record the ultraviolet-visible (UV-vis) spectra of the sample. UV-vis spectra were recorded at $1 \mathrm{~nm} / \mathrm{min}$ scan rate. A Cary Eclipse fluorescence spectrophotometer (serial no. MY14270004) was used to record the fluorescence spectra of the sample. The spectrophotometer uses a xenon flash lamp for superior sensitivity, high signal-to-noise ratio, and fast kinetics. Fluorescence spectra were recorded at every $12.5 \mathrm{~ms}$ and scanned at $24000 \mathrm{~nm} / \mathrm{min}$ without peak shifts.

Field-emission scanning electron microscopy (FESEM) images were recorded using a Carl Zeiss-Sigma field-emission microscope operating at an acceleration voltage of $3 \mathrm{kV}$. Samples were prepared by drop-casting the polymer solution on a silver foil. The samples were sputtered with gold before recording the images.

Transmission electron microscopy (TEM), high-resolution TEM (HRTEM), and high-angle annular dark-field scanning TEM (STEM) data were recorded on the JEOL JEM-2100 and FEI Tecnai G2 F20 electron microscopes operating at $200 \mathrm{kV}$. For the TEM and HRTEM measurements, a drop of the PAHz$\mathrm{DH}-\mathrm{Ag} \mathrm{NP}$ and PAHz-DH-Ag-Au NP solution was dispensed onto a $3 \mathrm{~mm}$ carbon-coated copper grid. Excess solution was removed with an absorbent paper, and the sample was dried under vacuum at room temperature. An energy-dispersive X-ray spectroscopy (EDX/EDS) analyzer attached to the TEM operating in the STEM mode was used to analyze PAHzDH-Ag NPs and PAHz-DH-Ag-Au NPs. The selected-area electron diffraction (SAED) and ring diffraction patterns of $\mathrm{PAHz}-\mathrm{DH}-\mathrm{Ag}-\mathrm{Au} \mathrm{NPs}$ were analyzed using a CrysTBox tool. $^{33}$

The size distribution curves of the particles present in the solutions were measured by the dynamic light scattering (DLS) approach using a Zetasizer Nano-ZS instrument (Malvern) equipped with a green laser $(523 \mathrm{~nm})$. The intensity of scattered light was detected at an angle of $173.1^{\circ}$. For each sample, three measurements were performed. The data processing was carried out using the Zetasizer software 7.10 (Malvern Instruments). The size distributions were reported as volume and number distributions.

Time-resolved fluorescence intensity decays were obtained using a commercial time-correlated single photon counting setup (LifeSpec II, Edinburgh Instruments, U.K.). All samples were excited at $376 \mathrm{~nm}$, and the full width at half-maxima of the instrument response function (IRF) is 110 ps. For lifetime measurements, peak counts of 4096 were collected with the emission polarizer oriented at magic-angle polarization, and decays were collected at $506 \mathrm{~nm}$. The time-resolved fluorescence intensity decays were analyzed by deconvoluting the observed decays with the IRF to obtain the intensity decay function, manifested as a sum of three exponentials for the present study. ${ }^{34}$

Synthesis of PAHz. PAHz was synthesized following a previously reported procedure. $^{28}$

Synthesis of PAHz-DH. To an aqueous solution of $\mathrm{PAHz}$ $(0.02 \mathrm{~g} / \mathrm{mL})$ in $2 \mathrm{~mL}$ of deionized water, $\mathrm{DC}(0.47 \mathrm{mM})$ was 
added at room temperature, and the mixture was stirred for 40 min. The progress of the reaction was monitored by UV-vis and fluorescence spectrophotometer. The plateauing of fluorescence intensity at $506 \mathrm{~nm}$ was considered to be completion of the reaction and formation of PAHz-DH.

Synthesis of PAHz-DH-Ag NPs. A typical synthetic procedure is described below. The aqueous solution of PAHz-DH $(0.02 \mathrm{~g} / \mathrm{mL})$ and $\mathrm{AgNO}_{3}(30 \mu \mathrm{M})$ was mixed together and stirred at room temperature for $30 \mathrm{~min}$. The color of the solution turned to light yellow, suggesting the PAHz$\mathrm{DH}-\mathrm{Ag}$ NP formation. The characterizations of PAHz-DH-Ag NPs were done by using UV-vis, fluorescence, TEM, DLS, and SEM analyses.

Sensing of Different Metal Ions. To confirm the selectivity of the sensor, various metal ions $\left(\mathrm{Au}^{3+}, \mathrm{Cs}^{3+}, \mathrm{Ca}^{2+}\right.$, $\mathrm{Co}^{2+}, \mathrm{Cu}^{2+}, \mathrm{Cd}^{2+}, \mathrm{Fe}^{2+}, \mathrm{Mg}^{2+}, \mathrm{Ni}^{2+}, \mathrm{Zn}^{2+}, \mathrm{Ag}^{+}, \mathrm{Pt}^{2+}, \mathrm{Hg}^{2+}, \mathrm{Sn}^{2+}$, $\mathrm{Cr}^{3+}, \mathrm{Ti}^{4+}$, and $\left.\mathrm{Pb}^{2+}\right)(20-800 \mathrm{pM})$ were added to an aqueous solution of PAHz-DH-Ag NP $(0.02 \mathrm{~g} / \mathrm{mL})$, and the fluorescence was recorded after $40 \mathrm{~s}$ of the addition of metal ions. The change in intensity versus metal ion concentration was monitored to understand the sensing efficiency of the PAHz-DH-Ag NPs.

Culture and Maintenance of HEK293 Cells. HEK293 cells were grown in Dulbecco's modified Eagle's medium (DMEM) supplemented with 10\% fetal bovine serum (FBS). All cells were supplemented with an antibiotic-antimycotic solution (100 units penicillin, $0.1 \mathrm{mg} \mathrm{mL}^{-1}$ streptomycin, and $0.25 \mathrm{mg} \mathrm{mL}^{-1}$ amphotericin B) and grown at $37{ }^{\circ} \mathrm{C}$ under standard cell culture conditions ( $5 \% \mathrm{CO}_{2}, 95 \%$ humidity). HEK293T cells were adhered to the cover slip for $24 \mathrm{~h}$ before the study.

Fluorescent Confocal Imaging. HEK293 cells after 20 min incubation with dye-labeled $\mathrm{Ag}$ or $\mathrm{Ag}-\mathrm{Au} \mathrm{NPs}$ at $\mathrm{pH} 8.0$ or 5.4 with appropriate controls were washed with $1 \times$ phosphate-buffered saline (PBS) and were fixed with $4 \%$ paraformaldehyde for $20 \mathrm{~min}$ at $40{ }^{\circ} \mathrm{C}$. Imaging was done using an Olympus BX61-FV1200-MPE microscope equipped with a $405 \mathrm{~nm}$ laser using $40 \times$ oil (1.3NA) objective with $8.0 \mu \mathrm{s} /$ pixel scan speed or by a fluorescent microscope Leica DMI6000 20X objective. Cropped images were assembled for presentation in Adobe Photoshop (version 7.1).

XTT Assay. HEK293 cells were grown in complete culture media (DMEM with $10 \%$ FBS) in 5\% $\mathrm{CO}_{2}$ and $95 \%$ humidity at $37^{\circ} \mathrm{C}$. The cells were seeded into 96 -well plates at a density of 50000 cells per well in culture media, and then $1 \mu \mathrm{M}, 500$ $\mu \mathrm{M}$, and $1 \mathrm{mM}$ concentrations were added in quadruplicates of PAHz-DH-Ag-Au NPs. The cells were incubated with the NPs for $20 \mathrm{~min}$ after which the medium was removed and fresh medium was added along with the kit reagents as followed in the kit protocol (cell proliferation kit II, Roche, Cat no. 11465015001). After $6 \mathrm{~h}$ incubation with the reagent, absorbance was measured using an ELISA plate reader at 480 nm.

Fluorescent Imaging. HEK293 cells after $60 \mathrm{~min}$ preincubation with $\mathrm{Au}$ NPs with appropriate controls were washed with $1 \times \mathrm{PBS}$ and were fixed with $4 \%$ paraformaldehyde for $20 \mathrm{~min}$ at $40{ }^{\circ} \mathrm{C}$. Imaging was done using a fluorescent microscope Leica DMI6000 $20 \times$ and $40 \times$ objective. The dye was excited using filters with excitation in the range of 340-380 $\mathrm{nm}$, and emission was collected at $425 \mathrm{~nm}$. The Au NP preincubated HEK293 cells were further incubated for $30 \mathrm{~min}$ with $\mathrm{PAHz}-\mathrm{DH}-\mathrm{Ag}$ NPs. The cells were washed with $1 \times \mathrm{PBS}$ and were fixed with $4 \%$ paraformaldehyde for $20 \mathrm{~min}$ at $40^{\circ} \mathrm{C}$, and images were recorded.

\section{RESULTS AND DISCUSSION}

$\mathrm{DH}$ was covalently labeled to $\mathrm{PAHz}$ by reacting $\mathrm{DC}$ $\left(\mathrm{CONHNH}_{2} / \mathrm{DC}=500: 1, \mathrm{~mol} / \mathrm{mol}\right)$ with $\mathrm{PAHz}$ in aqueous solution at $25{ }^{\circ} \mathrm{C}$ (Figure 1). Appearance of an absorption

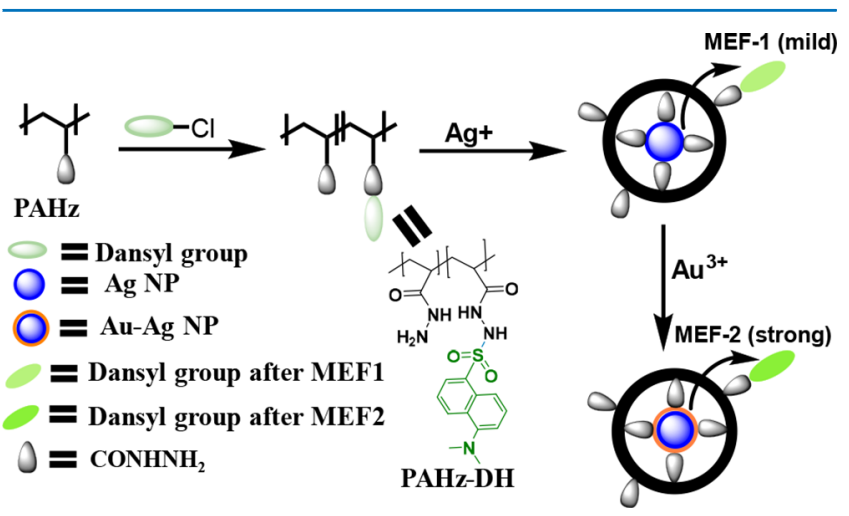

Figure 1. Schematic representation of DH labeling to $\mathrm{PAHz}$ followed by the formation of $\mathrm{Ag}$ and $\mathrm{Ag}-\mathrm{Au}$ NPs and the MEF of $\mathrm{DH}$ by the NPs.

maximum $\left(\lambda_{\max }\right)$ at $330 \mathrm{~nm}$ after $5 \mathrm{~min}$ of reaction time suggested the formation of $\mathrm{PAHz}-\mathrm{DH}$ (Figure 2A). The intensity of emission maxima at $506 \mathrm{~nm}$ gradually increased with time and reached a plateau after $30 \mathrm{~min}$, suggesting the completion of reaction (Figure $2 \mathrm{~B}$ ). ${ }^{a}$

The PAHz-DH-Ag NPs were synthesized by the in situ reduction of $\mathrm{Ag}^{+}$in the PAHz-DH solution by the $\mathrm{CONHNH}_{2}$ functionality and capping of the resulting $\mathrm{Ag} \mathrm{NP}$ with $\mathrm{CONHNH}_{2}$ as similarly reported recently. ${ }^{28}$ The $\lambda_{\max }$ at 410 $\mathrm{nm}$ attributable to the surface plasmon band of $\mathrm{Ag} \mathrm{NP}$ appeared within $5 \mathrm{~min}$ of the addition of $\mathrm{Ag}^{+}$at $25{ }^{\circ} \mathrm{C}$ and reached a plateau by $30 \mathrm{~min}$ of reaction time (Supporting Information, Figure S1). The fluorescence intensity at $506 \mathrm{~nm}$ simultaneously increased with the formation of $\mathrm{Ag} \mathrm{NP}$, suggesting fluorescence enhancement of $\mathrm{DH}$ by the Ag NP. Because the MEF effect is sensitive to the thickness of the spacer layer and the concentration of the metal NPs, the enhancement factor was optimized by varying the $\left[\mathrm{Ag}^{+}\right]$and $[\mathrm{PAHz}]$ in solution. For a fixed $[\mathrm{PAHz}]$, the absorbance at 410 $\mathrm{nm}$ gradually increased with $\left[\mathrm{Ag}^{+}\right]$, suggesting an increase in $\mathrm{Ag}$ $\mathrm{NP}$ amount in solution (Figure 2C, Supporting Information, Figure S2). The fluorescence intensity was maximum for the PAHz-DH-Ag NPs prepared using $0.02 \mathrm{~g} / \mathrm{mL}$ PAHz in solution (Figure 2D, Supporting Information, Figure S3). For any particular $[\mathrm{PAHz}]$ in between 0.01 and $0.1 \mathrm{~g} / \mathrm{mL}$, optimum intensity was noticed in the presence of $15-50 \mu \mathrm{M}$ of $\left[\mathrm{Ag}^{+}\right]$. The fluorescence intensity of the samples strongly decreased on increasing the $\left[\mathrm{Ag}^{+}\right]$beyond $50 \mu \mathrm{M}$. Therefore, the PAHz-DHAg NPs synthesized using $0.02 \mathrm{~g} / \mathrm{mL}[\mathrm{PAHz}], 0.48 \mathrm{mM} \mathrm{DC}$, and $30 \mu \mathrm{M}\left[\mathrm{Ag}^{+}\right]$were used for further studies.

The above NPs were mostly spherical in nature with diameters in the range of $10-20 \mathrm{~nm}$ (Figure 3A). The average particle size $\left(d_{\text {avg }}\right)$ of the PAHz-DH-Ag NPs in solution was $\sim 61 \mathrm{~nm}$ with a polydispersity index value of 0.3 (Figure 3B, Supporting Information, Figure S4). The PAHz cavity thickness around the Ag NP was approximated to be half the difference between $d_{\text {avg }}$ values obtained from the DLS and TEM analyses and found to be $\sim 25 \mathrm{~nm}$. The FESEM analysis of the PAHz- 

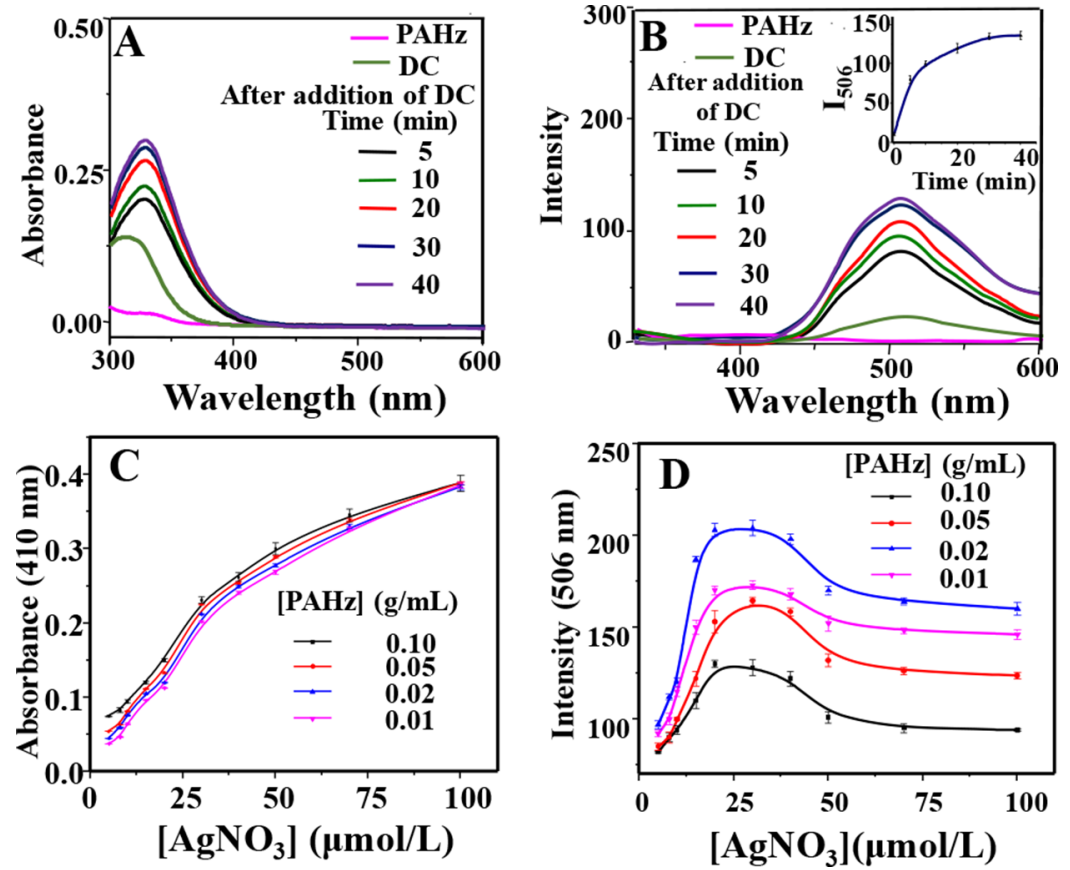

Figure 2. (A) UV-vis and (B) fluorescence traces of $\mathrm{PAHz}(0.02 \mathrm{~g} / \mathrm{mL})$ and $\mathrm{DC}(0.23 \mathrm{mM})$ in aqueous solution recorded after regular time intervals showing the gradual formation of PAHz-DH. Inset B: Variation of intensity at $506 \mathrm{~nm}$ with time. The effect of $\left[\mathrm{Ag}^{+}\right]$and $[\mathrm{PAHz}]$ on the (C) absorption maxima and (D) fluorescence intensity of DH in the resulting PAHz-DH-Ag NPs. $[\mathrm{PAHz}]=0.02 \mathrm{~g} / \mathrm{mL}$ and $[\mathrm{DC}]=0.48 \mathrm{mM}$ were maintained in the preparation of all the compositions. All the spectra were recorded after $30 \mathrm{~min}$ of the addition of $\mathrm{Ag}^{+}$to $\mathrm{PAHz}-\mathrm{DH}$ solution. The excitation wavelength was $325 \mathrm{~nm}$ for recording the fluorescence spectra. The fluorescence was monitored in the 335-650 nm range. The absorbance and intensity values presented in "C" and " $\mathrm{D}$ ", respectively, are the average of five experiments and are provided with error bars.

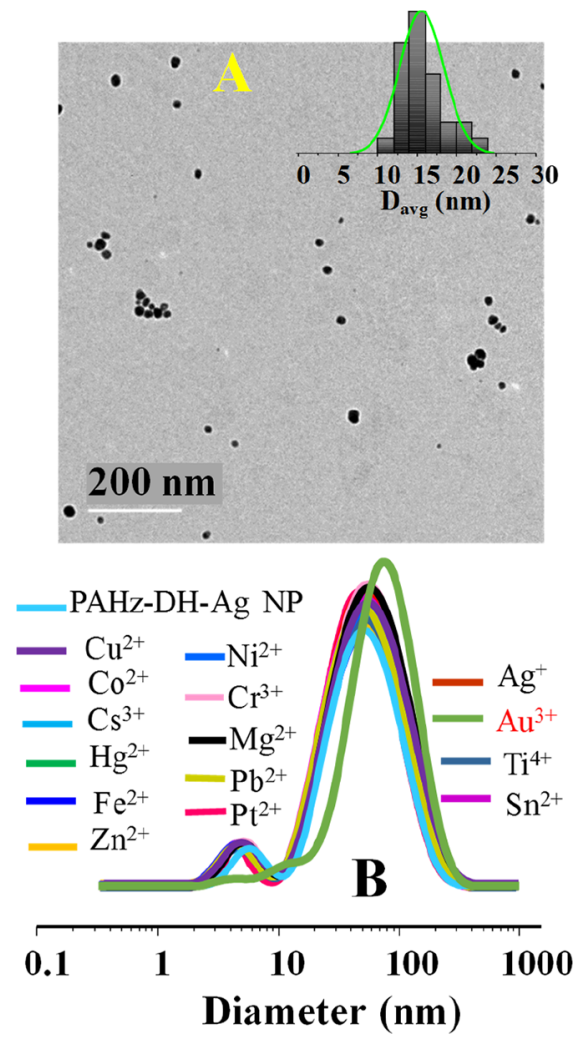

Figure 3. (A) TEM image of PAHz-DH-Ag NP synthesized using 0.02 $\mathrm{g} / \mathrm{mL}[\mathrm{PAHz}], 0.48 \mathrm{mM} \mathrm{DC}$, and $30 \mu \mathrm{M}\left[\mathrm{Ag}^{+}\right]$. Inset A: Particle size distribution of NPs. (B) DLS traces of PAHz-DH-Ag NP solution in the presence of various metal ions $(300 \mathrm{pM})$.
$\mathrm{DH}-\mathrm{Ag}$ NPs displayed uniform particles with diameters in the range of $40-80 \mathrm{~nm}$, supporting the DLS data (Supporting Information, Figure S5).

Various metal salts in picomolar amounts were added to the aqueous solution of PAHz-DH-Ag NP, and the change in spectroscopic properties was monitored. In the presence of 40 $\mathrm{pM} \mathrm{Au}{ }^{3+}$ in the PAHz-DH-Ag NP solution, a $\lambda_{\max }$ at $537 \mathrm{~nm}$ accountable to the surface plasmon band of Au NP appeared, suggesting the formation of $\mathrm{Ag}-\mathrm{Au}$ bimetallic NP (Figure 4A). The increase in absorbance of the $\lambda_{\max }$ at $537 \mathrm{~nm}$ with $\mathrm{Au}^{3+}$ amount and the isosbestic point at $465 \mathrm{~nm}$ supported the gradual deposition of $\mathrm{Au}$ on the Ag NP surface. The TEM image displayed the $d$-spacing values for both $\mathrm{Ag}(2.22 \AA)$ and $\mathrm{Au}(2.35 \AA)$ and supported the formation of $\mathrm{Ag}-\mathrm{Au}$ bimetallic NP (Figure 4B). The spherical shape of the Ag NPs changed to prism on the formation of $\mathrm{Ag}-\mathrm{Au}$ bimetallic NP. The UV-vis trace of the resulting PAHz-DH-Ag-Au NP was similar to that of the $\mathrm{Ag}-\mathrm{Au}$ nanoprism reported earlier. ${ }^{35}$ The EDS elemental mapping revealed the presence of both $\mathrm{Ag}$ and $\mathrm{Au}$ in the NP, and the overlay mapping suggested the presence of $\mathrm{Au}$ on the surface (Figure 4C-E, Supporting Information, Figure S6). The ratio between $\mathrm{Ag}$ and $\mathrm{Au}$ was measured to be 99.92:0.08 (w/w) (Supporting Information, Figure S7).

The $d_{\text {avg }}$ value of the PAHz-DH-Ag NP increased to $80 \mathrm{~nm}$ in the presence of $300 \mathrm{pM} \mathrm{Au}{ }^{3+}$, supporting the formation of the above bimetallic NP (Figure 3B). The formation of the corresponding $\mathrm{Ag}-\mathrm{Au} \mathrm{NP}$ is associated with the oxidation of carbonyl hydrazide functionality of PAHz. However, because the amount of $\mathrm{CONHNH}_{2}$ functionality $(\mathrm{mM})$ present in the solution is $\sim 10^{10}$ times higher than that of $\mathrm{Au}^{3+}$ (pM) added to the solution, the oxidative change may be negligible, and the $\mathrm{PAHz}$ cavity thickness is assumed to remain unaltered during the NP formation process. The $d_{\text {avg }}$ gradually increased from 

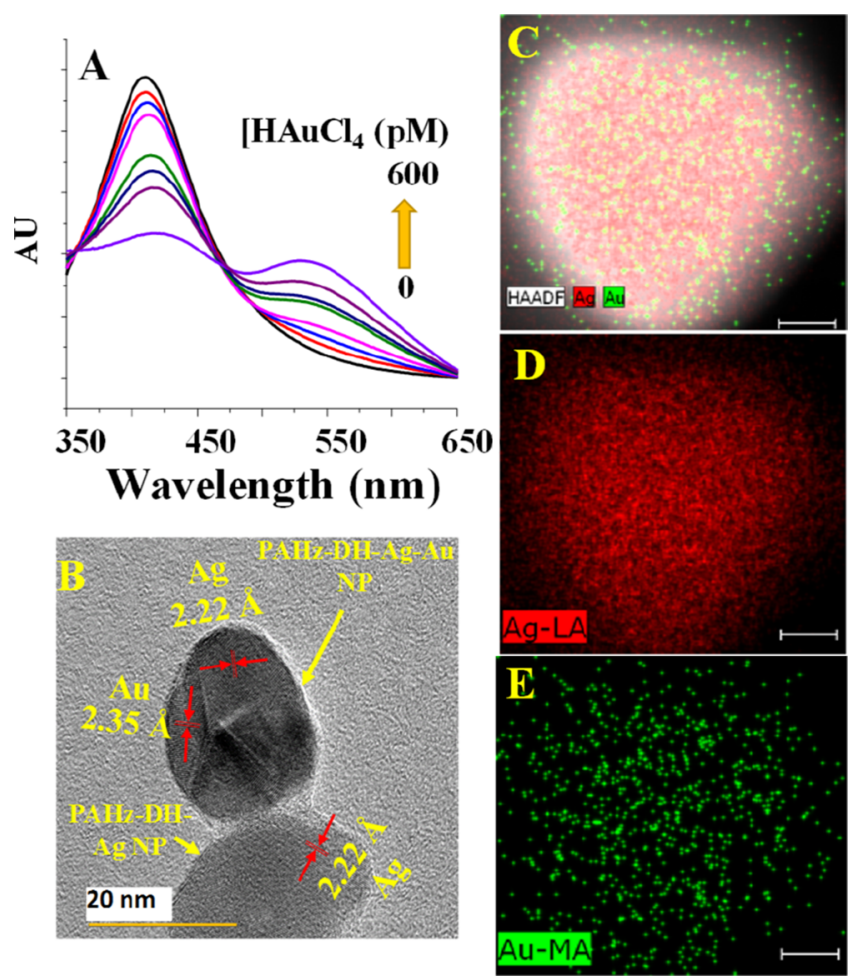

Figure 4. (A) UV-vis traces of PAHz-DH-Ag NP $(0.02 \mathrm{~g} / \mathrm{mL})$ in the presence of different amounts of $\mathrm{Au}^{3+}$, (B) TEM image of PAHz-DH$\mathrm{Ag}-\mathrm{Au} \mathrm{NP}$, EDS elemental mapping of (D) $\mathrm{Ag}$, (E) $\mathrm{Au}$, and (C) overlay mapping of PAHz-DH-Ag-Au NPs prepared using $0.02 \mathrm{~g} / \mathrm{mL}$

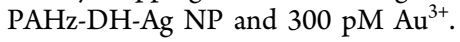

$\sim 63$ to $\sim 119 \mathrm{~nm}$ on increasing $\left[\mathrm{Au}^{3+}\right]$ and from 25 to $800 \mathrm{pM}$ in the PAHz-DH-Ag NP $(0.02 \mathrm{~g} / \mathrm{mL})$ solution, suggesting that the amount of $\mathrm{Au}^{3+}$ in the solution controlled the Au thickness in the resulting $\mathrm{Ag}-\mathrm{Au}$ bimetallic NPs (Supporting Information, Figure S4). The SAED image supported the presence of both the metals and the crystalline nature of the bimetallic NPs (Supporting Information, Figure S8).

To realize the possibility of the $\mathrm{Ag}-\mathrm{Au}$ alloy NP formation using the procedure, both $\mathrm{Ag}^{+}$and $\mathrm{Au}^{3+}$ in different molar proportions were added together to the $\mathrm{PAHz}$ solution $(0.02 \mathrm{~g} /$ $\mathrm{mL}$ ), and the mixture was incubated at $40{ }^{\circ} \mathrm{C}$ for $2 \mathrm{~h}$. The UVvis analysis revealed a single plasmon band for each of the compositions (Figure 5A). The $\lambda_{\max }$ gradually red-shifted from 425 to $545 \mathrm{~nm}$ on increasing the $\mathrm{Au}^{3+}$ content in the reacting mixture, suggesting the formation of the $\mathrm{Ag}-\mathrm{Au}$ alloy $\mathrm{NP}$ (Figure 5B). The dependence of absorption maxima on the ratio between $\mathrm{Ag}$ and $\mathrm{Au}$ content in alloy NPs is welldocumented in the literature. $^{36,37}$ The absorbance values of the $\mathrm{Ag}-\mathrm{Au}$ alloy NPs were lower than that of the Ag and Au NP, which supported the theoretical values calculated by using the Mie equation. ${ }^{38}$

The fluorescence signal of $\mathrm{DH}$ further improved with increase in $\left[\mathrm{Au}^{3+}\right]$, suggesting successive MEF by the $\mathrm{Ag}-\mathrm{Au}$ NP (Figure 6A). A noticeable increase in fluorescence intensity at $506 \mathrm{~nm}$ occurred in the presence of $40 \mathrm{pM} \mathrm{Au}^{3+}$ within $\sim 5 \mathrm{~s}$. The intensity value reached a plateau within $40 \mathrm{~s}$ of the addition of $\mathrm{Au}^{3+}$ (Supporting Information, Figure S9). Recently, a boron-dipyrromethene (BODIPY) Schiff base has been reported for instant turn-on detection of $\mathrm{Au}^{3+}$ in the nanomolar concentration. ${ }^{39}$ Nanoporous alumina-based interferometric sensor is also used for instant detection of

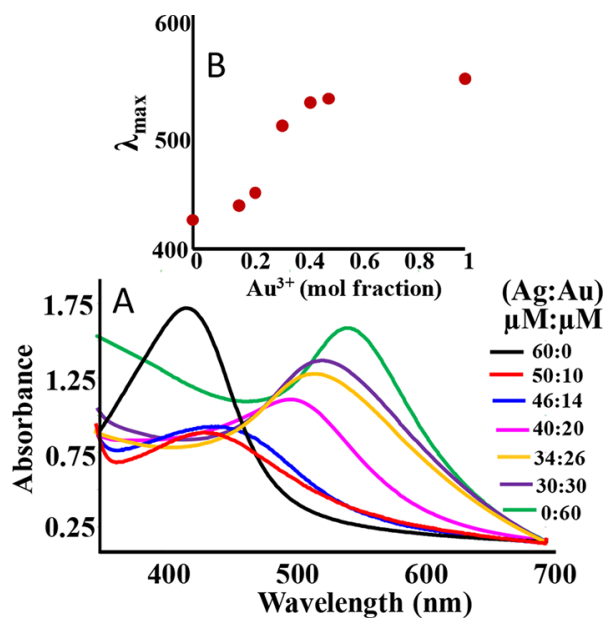

Figure 5. (A) Surface plasmon band of the PAHz-DH-Ag-Au alloy $\mathrm{NP}$ synthesized by adding different molar proportions of $\mathrm{Ag}^{+}$and $\mathrm{Au}^{3+}$ together $(60 \mu \mathrm{M})$ to the PAHz-DH solution $(0.02 \mathrm{~g} / \mathrm{mL})$. The spectra were recorded after incubating the mixture at $40{ }^{\circ} \mathrm{C}$ for $2 \mathrm{~h}$. (B) Effect of $\mathrm{Au}^{3+}$ mol fraction in $\mathrm{Ag}^{+}$and $\mathrm{Au}^{3+}$ mixture on the absorption maxima of the corresponding PAHz-DH-Ag-Au alloy NP.

micromolar amount of $\mathrm{Au}^{3+} .8$ The current procedure allows real-time monitoring of $\mathrm{Au}^{3+}$ and higher sensitivity compared to that of the existing procedures. Optimum enhancement ( $\sim$ fivefold) was noticed for $\left[\mathrm{Au}^{3+}\right]$ in the range of $100-300$ $\mathrm{pM}$ (Figure 6B). The color of the solution also appeared to be green under UV light, suggesting that these PAHz-DH-Ag NPs may be used for fluorescence sensing of picomolar amount of $\mathrm{Au}^{3+}$ in turn-on fashion (Figure 6C). A range of other metal ions in molar proportions $(100 \mathrm{pM})$ similar to that of $\mathrm{Au}^{3+}$ were also added to the PAHz-DH-Ag NP solution, and fluorescence data were recorded after $\sim 40 \mathrm{~s}$ of incubation period. The fluorescence enhancement was selective to $\mathrm{Au}^{3+}$ only among the 17 metal ions studied (Figure 6D, Supporting Information, Figure S10). The interference of other metal ions toward the sensing of $\mathrm{Au}^{3+}$ was investigated by adding $\mathrm{Au}^{3+}$ $(100 \mathrm{pM})$ to the PAHz-DH-Ag NP solution $(0.02 \mathrm{~g} / \mathrm{mL})$ along with another metal ion $(100 \mathrm{pM})$ in the same molar proportion. The UV-vis and fluorescence traces remained mostly unaffected by the presence of other ions, suggesting that the sensing is robust and insensitive toward the presence of other metal ions. In fact, the sensing of $\mathrm{Au}^{3+}$ was equally efficient in the presence of multiple metal ions (Supporting Information, Figure S11). The interference of other metal ions toward the $d_{\text {avg }}$ value of the resulting PAHz-DH-Ag-Au NP was also negligible, suggesting that the deposition of $\mathrm{Au}$ on the $\mathrm{Ag}$ NP was least affected by the presence of other metal ions in solution (Supporting Information, Figure S12).

The ultrasensitivity of PAHz-DH-Ag NPs toward $\mathrm{Au}^{3+}$ may have resulted from a strong interaction between the dye and the NP through the matching of surface plasmon band of the $\mathrm{Au}$ NP $(537 \mathrm{~nm})$ with that of the emission band of DH (506 $\mathrm{nm}) .{ }^{40}$ Spectral overlap between the fluorophore and plasmonresonant metal NPs is known to reinforce their fluorescence properties. ${ }^{41}$ The color of the PAHz-DH-Ag NP solution (0.02 $\mathrm{g} / \mathrm{mL}$ ) turned green under UV light within $5 \mathrm{~s}$ of the addition of $75 \mathrm{pM}$ or higher $\mathrm{Au}^{3+}$ (Figure $6 \mathrm{C}$ ). The $\mathrm{QY}=K_{\mathrm{rad}} /\left(K_{\mathrm{rad}}+\right.$ $\left.K_{\text {non-rad }}\right)$ of the resulting PAHz-DH-Ag-Au NP increased to 0.49 from 0.07 (PAHz-DH-Ag NP) (Figure 7, Supporting Information, Table S1). Interestingly, the average fluorescence lifetime $\left[\tau=1 /\left(K_{\text {rad }}+K_{\text {non-rad }}\right)\right]$ of the PAHz-DH-Ag-Au NPs 

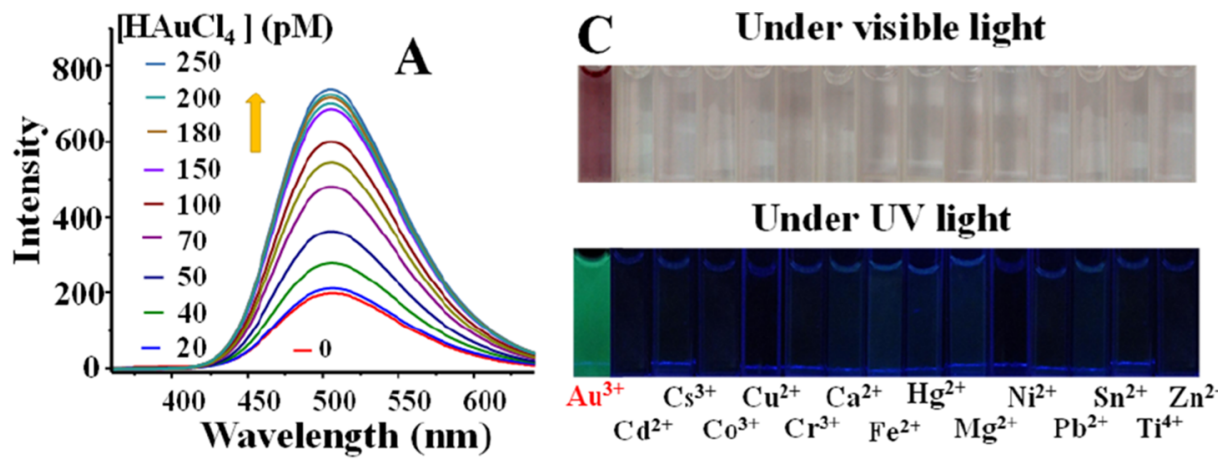

Under UV light
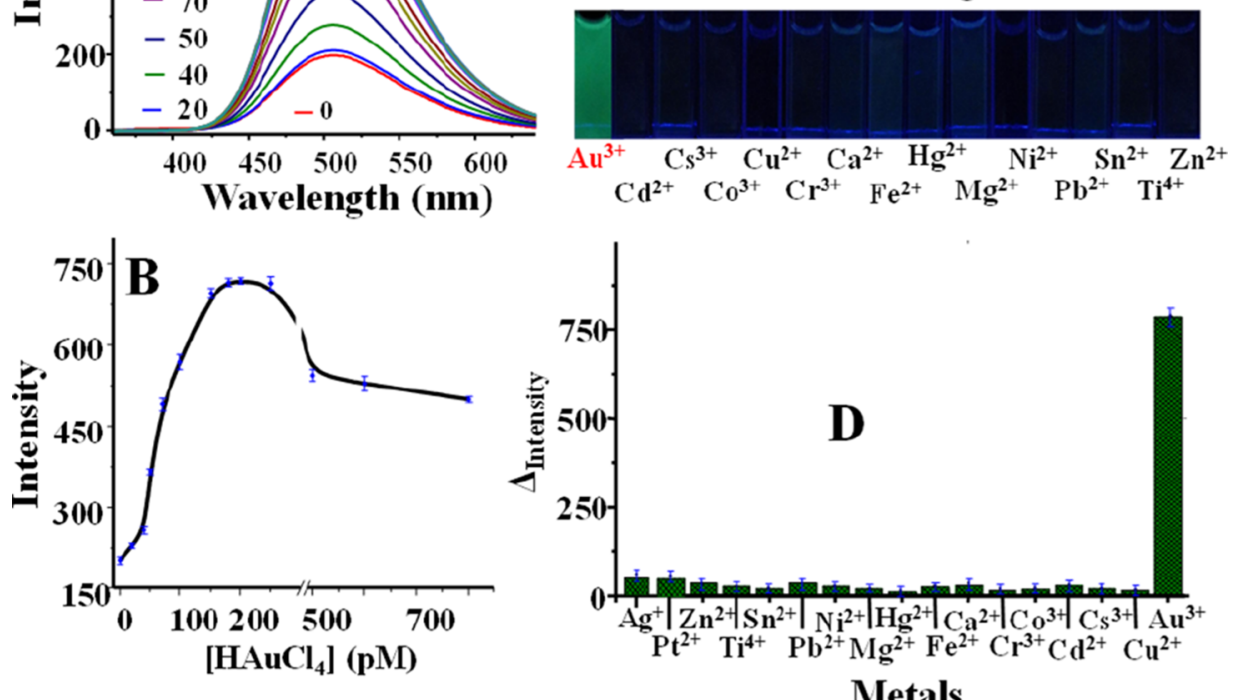

Figure 6. (A) Fluorescence spectra of PAHz-DH-Ag NP solution $(0.02 \mathrm{~g} / \mathrm{mL})$ in the presence of different $\mathrm{Au}^{3+}$ concentrations. The excitation wavelength was $325 \mathrm{~nm}$. The fluorescence was monitored in the $335-650 \mathrm{~nm}$ range. (B) Effect of [Au $\left.{ }^{3+}\right]$ on the fluorescence intensity of PAHz-DH$\mathrm{Ag}$ NP $(0.02 \mathrm{~g} / \mathrm{mL})$. The intensity values reported are an average of five experiments. (C) Color of the PAHz-DH-Ag NP solution under UV light in the presence of $75 \mathrm{pM}$ metal ions and under visible light in the presence of $450 \mathrm{nM}$ metal ions, (D) variation in fluorescence intensity at $506 \mathrm{~nm}$ of the PAHz-DH-Ag NP solution in the presence of different metal ions (100 pM). The incubation time was $40 \mathrm{~s}$ for all the metal ions. The values in "B" and "D" are provided with error bars.

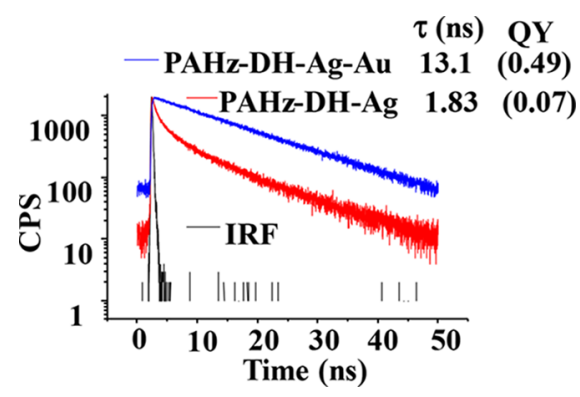

Figure 7. Fluorescence decay profile of PAHz-DH-Ag and PAHz-DH$\mathrm{Ag}-\mathrm{Au}$ NPs. Inset: QY and average lifetime $(\tau)$ data of both the NPs.

$(\sim 13.1 \mathrm{~ns})$ also experienced a sevenfold increase compared to that of the PAHz-DH-Ag NP (1.8 ns). Possibly, the replacement of $\mathrm{Ag}$ with $\mathrm{Ag}-\mathrm{Au} \mathrm{NP}$ has not substantially altered the radiative decay rate $\left(K_{\mathrm{rad}}\right)$ of the fluorophore. Other quenching processes including aggregation of fluorophores may also be minimal because of the covalent attachment of the dye to the $\mathrm{PAHz}$ cavity and fairly low concentration of $\mathrm{DH}(\mathrm{DH} /$ $\mathrm{CONHNH}_{2}=1: 500, \mathrm{~mol} / \mathrm{mol}$ ) in the solution. Therefore, the $\mathrm{QY}$ and $\tau$ changed proportionally to each other.

We have previously shown that PAHz-Ag NPs are $\mathrm{pH}$ responsive and are capable of penetrating and delivering drugs in cancer cells. ${ }^{28}$ The $\mathrm{pH}$-responsive fluorescent properties of a porphyrin moiety in the vicinity of $\mathrm{PAHz}-\mathrm{Ag}$ NPs have also been reported recently. ${ }^{42}$ The $\mathrm{pH}$ responsiveness of the optical properties of the luminescent $\mathrm{PAHz}-\mathrm{DH}-\mathrm{Ag}-\mathrm{Au}$ bimetallic NPs synthesized in this report was investigated to explore their utility in cell imaging and tumor detection applications. Because the $\mathrm{pH}$ of the cancerous cell environment is $\sim 5.4$, the UV-vis and fluorescence spectra of the PAHz-DH-Ag-Au NP were recorded under $\mathrm{pH} 5.4$ conditions and compared to that of the data at $\mathrm{pH} 8.0(\mathrm{pH}$ of $0.02 \mathrm{~g} / \mathrm{mL} \mathrm{PAHz})$. The fluorescence intensity of the PAHz-DH-Ag-Au NP solution exhibited $\sim 12$ fold decrease on changing the $\mathrm{pH}$ from 8.0 to 5.4, whereas the change in the absorbance value associated with the above change in $\mathrm{pH}$ was marginal (Figure $8 \mathrm{~A}, \mathrm{~B}$ ). The $d_{\mathrm{avg}}$ value decreased by $\sim 43 \%$ on changing the $\mathrm{pH}$ to 5.4 , suggesting that the $\mathrm{PAHz}$ cavity thickness around the $\mathrm{Ag}-\mathrm{Au} \mathrm{NP}$ shrank under the acidic $\mathrm{pH}$ (Figure $8 \mathrm{C}$ ). The above change in the spacer thickness may have affected the MEF of the fluorophore in the system (Figure $8 \mathrm{~B}$ ). To understand the intracellular behavior of the PAHz-coated $\mathrm{Ag}-\mathrm{Au} \mathrm{NP}$, both PAHz-DH-Ag and PAHz$\mathrm{DH}-\mathrm{Ag}-\mathrm{Au}$ NPs were incubated for $20 \mathrm{~min}$ in HEK293 cells under $\mathrm{pH} 8.0$ and 5.4 conditions, and the confocal images were acquired. The fluorescence of PAHz-DH-Ag-Au NPs substantially increased compared to that of the PAHz-DH-Ag NPs in the cells, suggesting that the former may be used for cell imaging applications (Figure 8D1,D2). More importantly, the fluorescence of PAHz-DH-Ag-Au NPs notably decreased on changing the $\mathrm{pH}$ from 8.0 to 5.4 (Figure $8 \mathrm{D} 3$ ). These results suggested that $\mathrm{PAHz}-\mathrm{DH}-\mathrm{Ag}-\mathrm{Au} \mathrm{NPs}$ act as a $\mathrm{pH}$-dependent fluorescent sensor, which may have potential for the identification of solid tumors. We also performed the 2,3bis(2-methoxy-4-nitro-5-sulfophenyl)-5-[(phenylamino)carbonyl $]-2 H$-tetrazolium hydroxide (XTT) assay to see the effect of NPs on cytotoxicity. We used PAHz-DH-Ag-Au NPs for this assay because these have the highest concentration of metals. No cytotoxicity on HEK293 cells was noticed for NPs loading up to $500 \mu \mathrm{M}$ (Figure 8E). The HEK293 cells 

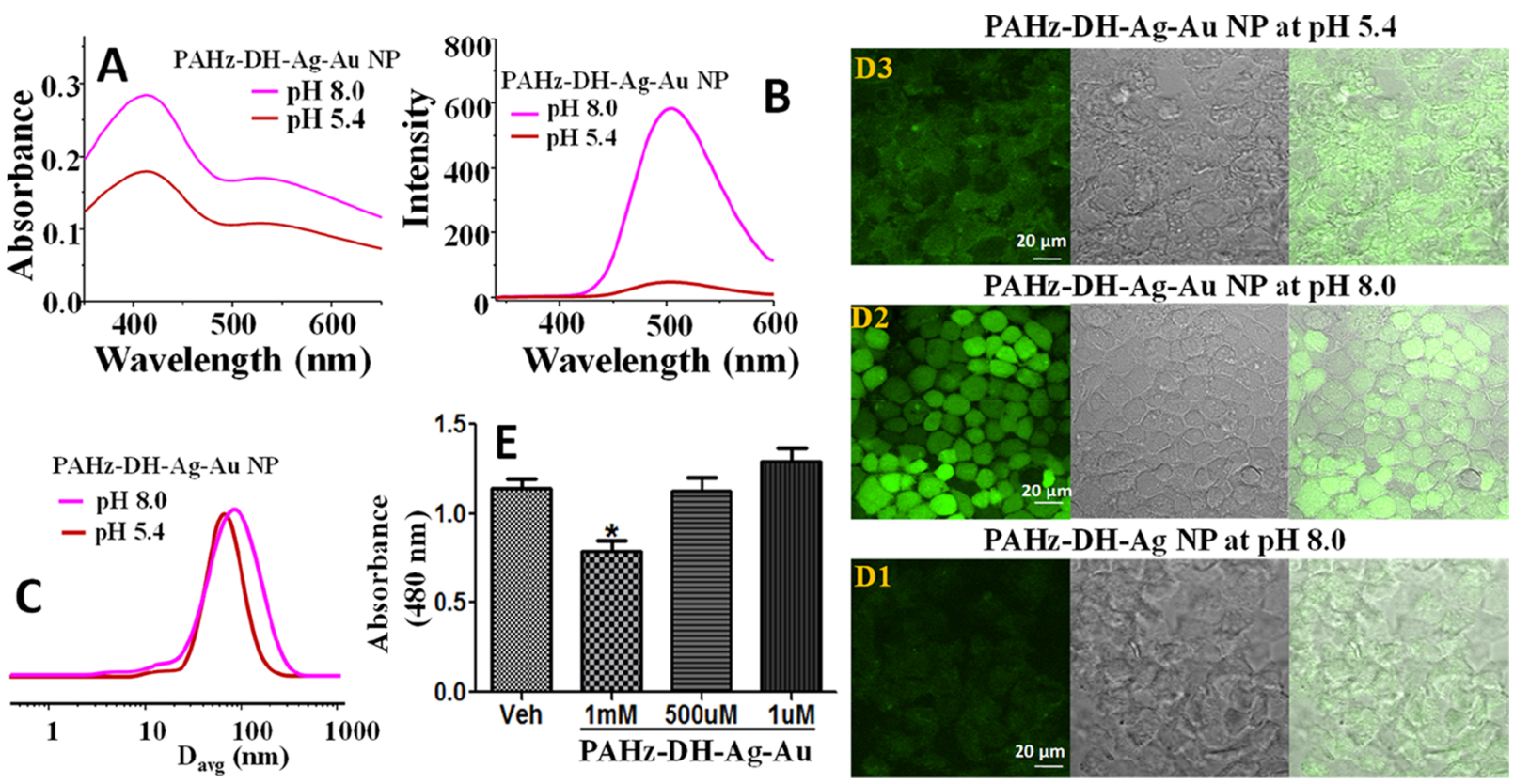

Figure 8. (A) UV-vis, (B) fluorescence spectra, and (C) DLS traces of PAHz-DH-Ag-Au NP solution under different pH conditions; the excitation wavelength for the fluorescence spectra was $325 \mathrm{~nm}$. The fluorescence was monitored in the 335-650 nm range. Confocal images of the HEK293 cells after incubation with (D1) PAHz-DH-Ag, (D2) PAHz-DH-Ag-Au NPs at pH 8.0, and (D3) PAHz-DH-Ag-Au NPs at pH 5.4 conditions, and the images were acquired using $40 \times$ objectives and a $405 \mathrm{~nm}$ laser. (E) XTT assay of the PAHz-DH-Ag-Au NPs. The experiment was conducted in quadruplicates, and the data show the mean \pm SEM of the absorbance at $480 \mathrm{~nm}$. $* p<0.05$ compared to vehicle by one-way ANOVA followed by Newman-Keuls post hoc analysis. Statistical analyses were performed using the Graphpad Prism 5 software.

preincubated with $\mathrm{Au}^{3+}$ for $1 \mathrm{~h}$ were exposed to the PAHz-DHAg NP probe.

As anticipated, the fluorescence of the probe increased in the cells, suggesting that these PAHz-DH-Ag NPs may be used for the intracellular detection of $\mathrm{Au}^{3+}$ (Supporting Information, Figure S13). These preliminary results suggest PAHz-DH-Ag$\mathrm{Au} \mathrm{NP}$ to be an important fluorescent biosensor for detecting the change in $\mathrm{pH}$ in cellular environments, which might have diagnostic potential for solid tumors.

\section{CONCLUSIONS}

The dye-labeled PAHz-capped Ag NP can be used as the reactive probe for instant fluorescent detection of picomolar amount of $\mathrm{Au}^{3+}$ in aqueous and biological environments. In the presence of $\mathrm{Au}^{3+}$, the PAHz-DH-Ag NP converts to the PAHz$\mathrm{DH}-\mathrm{Ag}-\mathrm{Au}$ bimetallic NP, and the fluorescence signal enhancement of $\mathrm{DH}$ occurs owing to strong MEF by $\mathrm{Au}$. The PAHz cavity thickness around the metal NP and the covalent attachment of the dye play important roles in optimizing the signal enhancement of the fluorophore. These bimetallic NPs are $\mathrm{pH}$-responsive and promptly change their size in response to change in $\mathrm{pH}$, which alters their optical properties. Owing to the above conditions, these fluorescentenhanced PAHz-DH-Ag-Au NPs may be used for cell imaging as well as optical detection of solid tumors. These bimetallic NPs are cytocompatible up to $500 \mu \mathrm{M}$ loading. This procedure may be extended to synthesize $\mathrm{Ag}-\mathrm{Au}$ alloy NPs. In future, drug may be loaded in these luminescent $\mathrm{pH}$-responsive alloy NPs for simultaneously diagnostic as well as therapeutic applications.

\section{ASSOCIATED CONTENT}

\section{S Supporting Information}

The Supporting Information is available free of charge on the ACS Publications website at DOI: 10.1021/acsomega.7b00857.

Fluorescence lifetime data, FESEM of PAHz-DH-Ag NP, DLS, UV-vis, cell culture, and SAED data (PDF)

\section{AUTHOR INFORMATION}

\section{Corresponding Author}

*E-mail: uojha@rgipt.ac.in. Phone: 09451959597 (U.O.).

\section{Present Address}

${ }^{\S}$ Current address: Rajiv Gandhi Institute of Petroleum Technology, Bahadurpur, Mukhetia More, Harbanshganj, Jais, Amethi, Uttar Pradesh-229304, India.

\section{Author Contributions}

The manuscript was written through contributions from all authors. All authors have given approval to the final version of the manuscript.

\section{Notes}

The authors declare no competing financial interest.

\section{ACKNOWLEDGMENTS}

We thank JEOL, India for the TEM analysis. C.S. thanks AcSIR for the fellowship. We thank DAE, India for providing partial financial assistance for the project.

\section{ADDITIONAL NOTE}

${ }^{a} \mathrm{DC}$ on reaction with $\mathrm{CONHNH}_{2}$ formed the $\mathrm{DH}$ moiety, which is fluorescent in nature, and the corresponding peak was observed at $506 \mathrm{~nm}$ and the intensity gradually increased with conversion of $\mathrm{DC}$ to $\mathrm{DH}$. 


\section{REFERENCES}

(1) Lee, H.; Lee, M.-Y.; Bhang, S. H.; Kim, B.-S.; Kim, Y. S.; Ju, J. H.; Kim, K. S.; Hahn, S. K. Hyaluronate-Gold Nanoparticle/tocilizumab Complex for the Treatment of Rheumatoid Arthritis. ACS Nano 2014, 8, 4790-4798.

(2) Goodman, C. M.; McCusker, C. D.; Yilmaz, T.; Rotello, V. M. Toxicity of Gold Nanoparticles Functionalized with Cationic and Anionic Side Chains. Bioconjugate Chem. 2004, 15, 897-900.

(3) Nam, S.-H.; Lee, W.-M.; Shin, Y.-J.; Yoon, S.-J.; Kim, S. W.; Kwak, J. I.; An, Y.-J. Derivation of Guideline Values for Gold (III) Ion Toxicity Limits to Protect Aquatic Ecosystems. Water Res. 2014, 48, 126-136.

(4) Marcon, G.; Carotti, S.; Coronnello, M.; Messori, L.; Mini, E.; Orioli, P.; Mazzei, T.; Cinellu, M. A.; Minghetti, G. Gold(III) Complexes with Bipyridyl Ligands: Solution Chemistry, Cytotoxicity, and DNA Binding Properties. J. Med. Chem. 2002, 45, 1672-1677.

(5) Bailes, J.; Gazi, S.; Ivanova, R.; Soloviev, M. Effect of Gold Nanoparticle Conjugation on the Activity and Stability of Functional Proteins. Methods Mol. Biol. 2012, 906, 89-99.

(6) Sabella, S.; Carney, R. P.; Brunetti, V.; Malvindi, M. A.; Al-Juffali, N.; Vecchio, G.; Janes, S. M.; Bakr, O. M.; Cingolani, R.; Stellacci, F.; Pompa, P. P. A General Mechanism for Intracellular Toxicity of MetalContaining Nanoparticles. Nanoscale 2014, 6, 7052-7061.

(7) Habib, A.; Tabata, M. Oxidative DNA Damage Induced by HEPES (2-[4-(2-Hydroxyethyl)-1-Piperazinyl]ethanesulfonic Acid) Buffer in the Presence of $\mathrm{Au}(\mathrm{III})$. J. Inorg. Biochem. 2004, 98, 16961702 .

(8) Kumeria, T.; Santos, A.; Losic, D. Ultrasensitive Nanoporous Interferometric Sensor for Label-Free Detection of Gold(III) Ions. ACS Appl. Mater. Interfaces 2013, 5, 11783-11790.

(9) Yuan, L.; Lin, W.; Yang, Y.; Song, J. A Fast-Responsive Fluorescent Probe for Detection of Gold Ions in Water and Synthetic Products. Chem. Commun. 2011, 47, 4703-4705.

(10) Dong, M.; Wang, Y.-W.; Peng, Y. Highly Selective Ratiometric Fluorescent Sensing for $\mathrm{Hg}^{2+}$ and $\mathrm{Au}^{3+}$, Respectively, in Aqueous Media. Org. Lett. 2010, 12, 5310-5313.

(11) Tseng, H.-W.; Tsai, Y.-J.; Yen, J.-H.; Chen, P.-H.; Yeh, Y.-C. A fluorescence-based microbial sensor for the selective detection of gold. Chem. Commun. 2014, 50, 1735-1737.

(12) Anker, J. N.; Hall, W. P.; Lyandres, O.; Shah, N. C.; Zhao, J.; Van Duyne, R. P. Biosensing with Plasmonic Nanosensors. Nat. Mater. 2008, 7, 442-453.

(13) Park, J.; Choi, S.; Kim, T.-I.; Kim, Y. Highly Selective Fluorescence Turn-on Sensing of Gold Ions by a Nanoparticle generation/C-I Bond Cleavage Sequence. Analyst 2012, 137, 44114414.

(14) Kong, D.; Liu, L.; Song, S.; Suryoprabowo, S.; Li, A.; Kuang, H.; Wang, L.; Xu, C. A gold nanoparticle-based semi-quantitative and quantitative ultrasensitive paper sensor for the detection of twenty mycotoxins. Nanoscale 2016, 8, 5245-5253.

(15) (a) Jeong, H.-H.; Mark, A. G.; Alarcón-Correa, M.; Kim, I.; Oswald, P.; Lee, T.-C.; Fischer, P. Dispersion and Shape Engineered Plasmonic Nanosensors. Nat. Commun. 2016, 7, 11331. (b) Lal, S.; Link, S.; Halas, N. J. Nano-Optics from Sensing to Waveguiding. Nat. Photonics 2007, 1, 641-648.

(16) Perfézou, M.; Turner, A.; Merkoçi, A. Cancer Detection Using Nanoparticle-Based Sensors. Chem. Soc. Rev. 2012, 41, 2606-2622.

(17) Wei, X.; Chen, Z.; Tan, L.; Lou, T.; Zhao, Y. DNA-Catalytically Active Gold Nanoparticle Conjugates-Based Colorimetric Multidimensional Sensor Array for Protein Discrimination. Anal. Chem. 2017, 89, 556-559.

(18) Jiang, Z.; Le, N. D. B.; Gupta, A.; Rotello, V. M. Cell SurfaceBased Sensing with Metallic Nanoparticles. Chem. Soc. Rev. 2015, 44, 4264-4274.

(19) Lei, J.; Wang, L.; Zhang, J. Ratiometric pH Sensor Based on Mesoporous Silica Nanoparticles and Förster Resonance Energy Transfer. Chem. Commun. 2010, 46, 8445-8447.
(20) Kumar, A.; Kim, S.; Nam, J.-M. Plasmonically Engineered Nanoprobes for Biomedical Applications. J. Am. Chem. Soc. 2016, 138, 14509-14525.

(21) Wang, M.; Hou, X.; Wiraja, C.; Sun, L.; Xu, Z. J.; Xu, C. Smart Magnetic Nanosensors Synthesized through Layer-by-Layer Deposition of Molecular Beacons for Noninvasive and Longitudinal Monitoring of Cellular mRNA. ACS Appl. Mater. Interfaces 2016, 8, $5877-5886$

(22) Chinen, A. B.; Guan, C. M.; Ferrer, J. R.; Barnaby, S. N.; Merkel, T. J.; Mirkin, C. A. Nanoparticle Probes for the Detection of Cancer Biomarkers, Cells, and Tissues by Fluorescence. Chem. Rev. 2015, 115, 10530-10574.

(23) Chen, G.; Roy, I.; Yang, C.; Prasad, P. N. Nanochemistry and Nanomedicine for Nanoparticle-Based Diagnostics and Therapy. Chem. Rev. 2016, 116, 2826-2885.

(24) Bardhan, R.; Grady, N. K.; Cole, J. R.; Joshi, A.; Halas, N. J. Fluorescence Enhancement by Au Nanostructures: Nanoshells and Nanorods. ACS Nano 2009, 3, 744-752.

(25) Pollinger, K.; Hennig, R.; Ohlmann, A.; Fuchshofer, R.; Wenzel, R.; Breunig, M.; Tessmar, J.; Tamm, E. R.; Goepferich, A. LigandFunctionalized Nanoparticles Target Endothelial Cells in Retinal Capillaries after Systemic Application. Proc. Natl. Acad. Sci. U.S.A. 2013, 110, 6115-6120.

(26) Geddes, C. D.; Lakowicz, J. R. Editorial: Metal-Enhanced Fluorescence. J. Fluoresc. 2002, 12, 121-129.

(27) Szmacinski, H.; Badugu, R.; Mahdavi, F.; Blair, S.; Lakowicz, J. R. Large Fluorescence Enhancements of Fluorophore Ensembles with Multilayer Plasmonic Substrates: Comparison of Theory and Experimental Results. J. Phys. Chem. C 2012, 116, 21563-21571.

(28) Ujjwal, R. R.; Purohit, M. P.; Patnaik, S.; Ojha, U. General Reagent Free Route to pH Responsive Polyacryloyl Hydrazide Capped Metal Nanogels for Synergistic Anticancer Therapeutics. ACS Appl. Mater. Interfaces 2015, 7, 11497-11507.

(29) Kumar, A.; Ujjwal, R. R.; Mittal, A.; Bansal, A.; Ojha, U. Polyacryloyl Hydrazide: An Efficient, Simple, and Cost Effective Precursor to a Range of Functional Materials through Hydrazide Based Click Reactions. ACS Appl. Mater. Interfaces 2014, 6, 1855-1865.

(30) Dulkeith, E.; Morteani, A. C.; Niedereichholz, T.; Klar, T. A.; Feldmann, J.; Levi, S. A.; van Veggel, F. C. J. M.; Reinhoudt, D. N.; Möller, M.; Gittins, D. I. Fluorescence Quenching of Dye Molecules near Gold Nanoparticles: Radiative and Nonradiative Effects. Phys. Rev. Lett. 2002, 89, 203002.

(31) Zhang, J.; Lakowicz, J. R. Metal-Enhanced Fluorescence of an Organic Fluorophore Using Gold Particles. Opt. Express 2007, 15, $2598-2606$

(32) Tovmachenko, O. G.; Graf, C.; van den Heuvel, D. J.; van Blaaderen, A.; Gerritsen, H. C. Fluorescence Enhancement by MetalCore/silica-Shell Nanoparticles. Adv. Mater. 2006, 18, 91-95.

(33) Klinger, M.; Jäger, A. Crystallographic Tool Box (CrysTBox): Automated Tools for Transmission Electron Microscopists and Crystallographers. J. Appl. Crystallogr. 2015, 48, 2012-2018.

(34) Lakowicz, J. R. Principles of Fluorescence Spectroscopy, 3rd ed.; Springer: NY, 2006.

(35) Guisbiers, G.; Mendoza-Cruz, R; Bazán-Díaz, L.; VelázquezSalazar, J.; Mendoza-Perez, R.; Robledo-Torres, J. A.; RodriguezLopez, J.-L.; Montejano-Carrizales, J. M.; Whetten, R. L.; JoséYacamán, M. Electrum, the Gold-Silver Alloy, from the Bulk Scale to the Nanoscale: Synthesis, Properties, and Segregation Rules. ACS Nano 2016, 10, 188-198.

(36) Link, S.; Wang, Z. L.; El-Sayed, M. A. Alloy Formation of GoldSilver Nanoparticles and the Dependence of the Plasmon Absorption on Their Composition. J. Phys. Chem. B 1999, 103, 3529-3533.

(37) Chen, D.-H.; Chen, C.-J. Formation and Characterization of $\mathrm{Au}-\mathrm{Ag}$ Bimetallic Nanoparticles in Water-in-Oil Microemulsions. J. Mater. Chem. 2002, 12, 1557-1562.

(38) Mulvaney, P. Surface Plasmon Spectroscopy of Nanosized Metal Particles. Langmuir 1996, 12, 788-800. 
(39) Cheng, H.-r.; Qian, Y. A Novel BODIPY-Schiff Base-Based Colorimetric and Fluorometric Dosimeter for $\mathrm{Hg}^{2+}, \mathrm{Fe}^{3+}$ and $\mathrm{Au}^{3+}$. RSC Adv. 2015, 5, 82887-82893.

(40) Chen, J.; Jin, Y.; Fahruddin, N.; Zhao, J. X. Development of Gold Nanoparticle-Enhanced Fluorescent Nanocomposites. Langmuir 2013, 29, 1584-1591.

(41) Chen, Y.; Munechika, K.; Ginger, D. S. Dependence of Fluorescence Intensity on the Spectral Overlap between Fluorophores and Plasmon Resonant Single Silver Nanoparticles. Nano Lett. 2007, 7, 690-696.

(42) Yuan, S.; Ge, F.; Chen, Y.; Cai, Z. Tunable Metal-Enhanced Fluorescence by $\mathrm{pH}$-Responsive Polyacryloyl Hydrazide Capped Ag Nanoparticles. RSC Adv. 2017, 7, 6358-6363. 